\title{
LA EXPULSIÓN Y LA JUSTIFICACIÓN DE LA CONVERSIÓN SIMULADA *
}

\author{
FERNANDO DÍAZ ESTEBAN \\ Universidad Complutense. Madrid
}

\section{LAS EXPULSIONES EUROPEAS ANTERIORES}

Para entender la expulsión de los judíos de España es necesario situarla dentro de un proceso histórico común a toda Europa. No fue un hecho singular o insólito, sino una incorporación tardía de España a un creciente movimiento de intolerancia religiosa en Europa. La expulsión de los judíos de Castilla y de Aragón no fue ninguna novedad, puesto que la misma decisión ya la habían tomado los reyes de Inglaterra y de Francia mucho antes que los Reyes Católicos.

Como es sabido, la expulsión de los judíos de Inglaterra se realizó en 1290 y hasta 1655 no se comenzó a negociar su vuelta por el Lord Protector Oliver Cromwell y el portugués, de linaje converso, Manoel Dias Soeiro, que había judaizado en Amsterdam y tomado el nombre de Menasseh ben Israel ${ }^{1}$. Estuvieron, pues, cuatro siglos expulsados de Inglaterra y aunque volvieron tolerados como cristianos aparentes pero verdaderos judíos, hasta el siglo XIX no recibieron la plenitud de los derechos civiles. En España la Constitución de 1812 declaraba la libertad de religión y a su imitación las demás constituciones españolas así lo reconocieron. Los gobiernos españoles del siglo XIX, a pesar del agobio que representaba el tener que

* Comunicación leída el 26 de mayo de 1992 en el interesantísimo congreso «Le vie difficili della convivenza. Gli ebrei sul filo della storia» celebrado en Génova, 2527 mayo 1992, y cuyas Actas, según he sabido, por penosas razones no serán publicadas, por lo que ahora me acojo a la hospitalidad de Sefarad, pues sigo manteniendo las mismas ideas que ya expuse públicamente en 1978 y 1992.

1 Una documentada síntesis de la comunidad de Ámsterdam y de su vida y pensamiento se encuentra en la obra de Menasseh ben Israel: Esperanza de Israel, $\mathrm{H}$. MÉchoulan - G. NAHON (eds.), Madrid 1987. 
atender a la sublevación de las antiguas colonias americanas, a la reconstrucción del país devastado por la invasión napoleónica y a la guerra civil carlista, también se preocuparon por ayudar a los descendientes de los judíos expulsados y del modo de que volvieran a España, pero la desastrosa situación económica apenas permitió algo más que apoyo diplomático ${ }^{2} \mathrm{y}$ buenas palabras, aparte del permiso para establecerse en España a los judíos que lo desearan.

La expulsión de Inglaterra la achacan los historiadores judíos a la presión de los calumniadores sobre las autoridades. Así, Salomón ben Verga, que escribe en hebreo La verga de Judá (Šebet Yěhudâ) ${ }^{3}$ publicado en 1550 , dice (cap. 18) que la expulsión se debió a la acusación de recortar moneda; otra acusación, la de haber ayudado a un fraile enamorado de una judía a hacerse judío, la aplica erróneamente a Francia (cap. 20). Ambos motivos están recogidos en $E l$ valle del llanto de Yosef ha-Kohen (caps. 69 y 70) ${ }^{4}$, aunque estas acusaciones se correspondan a 1275 y 1278 y no fueron la causa inmediata de la expulsión del 18 de Julio de 1290.

De Francia, tras diversos intentos de poca duración (los más notables los de 1306-1315, 1322) fueron expulsados definitivamente en 1394. La verga de Judá ${ }^{5}$ hace referencia a las diversas expulsiones previas a la final (1394), de la cual nada dice en concreto, mientras que $E l$ valle del llanto, cuya última copia se terminó en Génova el 29 de Junio de 1575, sí trata de ella ${ }^{6}$. En Burdeos, Nantes, Ruán y algunos otros lugares vivieron como cristianos, tanto los conversos

\footnotetext{
${ }^{2}$ I. GonZÁLEZ, El retorno de los judíos, Madrid 1991. Los vaivenes políticos entre absolutistas y liberales retrasaron la abolición de la Inquisición hasta 1834; a partir de 1884 se establecen banqueros judíos; el paso de la formulación teórica liberal de 1812 a la práctica se inicia en 1860 durante la guerra de África con el encuentro de comunidades castellano-parlantes en Marruecos y los sucesos de Rusia de 1880 que afectaban a oriundos de España.

${ }^{3}$ La traducción castellana más antigua es La Vara de Juda compuesta por el Rab Šelomoh hijo de Verga en la lengua hebrea, y traducida en la española por M. de L., Amsterdam 1640 y 5504 [= 1744]; la segunda es la de F. CANTERA Burgos, Chébet Jehuda (La Vara de Judá) de Salomón ben Verga, Granada 1927; la última es la de M. ${ }^{a}$ J. CANo, Šelomoh ben Verga: La Vara de Yehudah (Sefer Šebeț Yehudah), Barcelona 1991.

${ }^{4}$ P. León Tello (trad.), 'Emeq ha-bakha de Yosef ha-Kohen, Madrid - Barcelona 1964, pág. 380.

${ }^{5}$ Caps. 21, 22, 23, 24 y 25.

${ }^{6}$ Yosef ha-Kohen dice textualmente "y no han vuelto ya a entrar en [esta maldita] Francia hasta hoy»; cf. P. LEÓN Tello (trad.), Op. cit., pág. 137.
} 
sinceros como los falsos o criptojudíos. Como es sabido, los conversos sinceros denunciaban a la Inquisición a sus convecinos y familiares retornados al judaísmo ${ }^{7}$. La enemistad entre uno y otro grupo en Ruán movió al cardenal Richelieu a decidir que los criptojudíos debían ser tolerados.

La fragmentación política de Italia durante la Edad Media y Moderna hacía que las expulsiones y readmisiones fueran locales, de poca duración y caprichosas, mientras que en los Estados Papales y en especial en Roma, la acogida de los judíos fue permanente. La expulsión de España trajo problemas a los judíos de Italia, que en ocasiones eran superados numérica o socialmente por los recién llegados, originándose tensiones entre los dos grupos. Podemos tomar como ejemplo a Génova. Según La verga de Judá (caps. 56 y 57), en un momento en que había una gran hambre en la ciudad llegó un barco con judíos expulsados de España que no habían sido admitidos en otras ciudades (en realidad, tampoco en Génova), pero aquí se les permitió desembarcar, aunque la mayoría de los llegados, hambrientos, se hicieron cristianos a cambio de pan para comer, visto lo cual marcharon a Roma, donde los judíos romanos se opusieron a su admisión hasta que el propio Papa intervino en favor de los recién llegados ${ }^{8}$. El valle del llanto cuenta la experiencia personal de su autor, que nacido en 1496 en Aviñón (cap. 133) llegó a Génova (Pilar León Tello piensa que primero a Novi) en 1501, cuando tenía cinco años de edad, y que, expulsados los judíos de Génova en 1516 por Octaviano Fregoso (cap. 137), se trasladó con la familia a Novi, donde se casó en 1518; los judíos pudieron volver a Génova en 1522 por decisión de los Adorno (cap. 140), pero Yosef ha-Kohen no vuelve; en 1524 está en Lerma (en el Piamonte) y en 1534 en Voltagio, desde donde se traslada a Génova en 1538 (cap. 148) y aquí se queda hasta la nueva expulsión de 1550 (cap. 161); se traslada a Voltagio, de donde una nueva expulsión (1567) le lleva a Castelleto de Monferrato (cap. 192), desde donde vuelve en 1557 a Génova. También en El valle del llanto nos cuenta que los marineros

\footnotetext{
${ }^{7}$ CH. Amiel, El siglo pitagórico, París 1977, ha señalado que la prisión de Antonio Enríquez Gómez en Sevilla, donde vivía con el nombre de Fernando de Zárate, se debió a una denuncia originada en Ruán.

${ }^{8}$ Sabido es el tono novelero y la invención de situaciones de Ibn Verga. Para el profesor R. Bonfil (según su participación en el Convegno) no solamente los detalles son inventados, sino también el hecho en sí.
} 
genoveses que traían en sus barcos a los expulsados de España, «aquella tierra maldita», los maltrataron y los vendieron como esclavos en Génova y sus aldeas anejas (cap. 117). Con todo, Italia fue una tierra donde pudieron rehacer sus vidas como judíos.

La posibilidad que ofrecía Italia de vivir públicamente como judíos se repetía un siglo después en Ámsterdam, donde paradójicamente la rígida disciplina calvinista permitía el asentamiento de una comunidad de conversos hispano-portugueses marranos o vueltos al judaísmo en diverso grado de ortodoxia 9 . Pocos elogios ha merecido una ciudad como la que le dedica Miguel de Barrios en su Luna opulenta de Holanda publicada en 1680:

Amsterdam es Babel de ciencias, Atenas de diferentes lenguas ... y su mayor lauro es que teniendo tan diversas gentes de opuestas religiones, se mantiene pacífica con pocos ministros, pero con mucha justicia ${ }^{10}$.

Portugal, que había servido de refugio a muchos judíos españoles, cambió de signo bajo el rey don Manuel, quien primero pensó en la expulsión de los judíos (1496) para acabar decretando el bautismo forzoso de su totalidad (1497); una vez todos bautizados, la expulsión no se llevó a cabo por falta legal de judíos.

En Alemania (y en el norte y centro de Europa en general), cabe más hablar de persecuciones y de prohibiciones de residencia que de expulsiones, aunque éstas no falten con carácter local. Sobre la actitud de los judíos de Askenaz o Centroeuropa hablaremos más adelante.

\section{LA TIBIEZA DE LOS CONVERSOS}

Es necesario distinguir entre el apóstata convencido de buena fe, que cree haber hallado a solas con su conciencia la verdad indudable, y el apóstata simulado. Sabido es que algunos de los apóstatas

\footnotetext{
${ }^{9}$ Recordemos que aunque los judíos tenían ciertas limitaciones en sus derechos ciudadanos, gozaban de una amplísima libertad. La formación inicial judía de los asentados era muy diversa, en parte por las dificultades que la Inquisición significaba, y además porque solían tener una educación intelectual cristiana.

${ }^{10}$ Luna opulenta de Holanda en nubes que Amor manda... Autor Don Miguel de Barrios..., Amsterdam (David Tartas) 1680, pág. 3, prosa.
} 
sinceros, como es el caso de Mošeh Sefardí de Huesca (Pedro Alfonso), Abner de Burgos (Alfonso de Valladolid) y Salomón Leví (Pablo de Santa María) entre otros muchos, llevaban su celo de neófitos a escribir obras polémicas contra sus antiguos correligionarios, mientras que otros, como es el caso de don Alfonso de Cartagena, intentaban vivir su fe cristiana con la mayor intensidad espiritual posible, sin rechazar sus orígenes. El apóstata simulado, por el contrario, finge haber cambiado de religión, pero en el fondo de su alma sigue apegado a la que antes tenía. El miedo, el interés económico y, a veces, un cierto grado de desorientación producen el apóstata simulado, mientras que el apóstata sincero arrostra, en ocasiones, peligros de muerte o de rechazo social y familiar. No es buena metodología la de los que a priori consideran al converso como sinónimo de apóstata fingido. La jurisprudencia judía en general, como ha señalado Orfali ${ }^{11}$, parte de la idea de que el converso «aunque pecó, Israel es», y hay que dejarle una puerta abierta para que retorne al judaísmo. Esta posibilidad de retorno sería para algunos desilusionados con su nueva fe una tentación permanente. La abundancia de falsos conversos produjo la idea general, entre el pueblo del tiempo de los Reyes Católicos y de después, de que el converso o era un tibio o era un apóstata fingido $\mathrm{y}$ en todo caso había que vigilarlo y, llegado el caso, castigarlo; y evitar asimismo su contacto con los judíos, como reconoce Isaac Cardoso ${ }^{12}$,

... no les imputaron crimen alguno de Lesa Magestad, ni de infidelidad, ni de otros delitos enormes, aunque salieron 120.000 familias, solo dizia visto como los judios de sus Estados induzian a judaizar a muchos christianos...

No se reparaba en la inhumanidad de la coacción para la conversión porque a todos les resultaba evidente que el que no quería hacerse cristiano podía no hacerse ${ }^{13}$. A pesar de ello no deja de sorprender-

\footnotetext{
11 M. Orfali Levi, Los conversos españoles en la literatura rabínica. Problemas jurídicos y opiniones legales durante los siglos XII-XVI, Salamanca 1982.

${ }^{12}$ Las Excelencias de los Hebreos por el Doctor Yshac Cardoso, Amsterdam 1679, pág. 372.

13 Y. Shamir, Rabbi Moses ha-Kohen of Tordesillas and his Book 'Ezer ha-Emunah. A Chapter in the History of the Judeo-Christian Controversy, Leiden 1975, pág. 29, cree con Netanyahu que la mayoría de las conversiones eran sinceras. El propio Moises de Tordesillas es un ejemplo de que quien quería podía resistir la coacción.
} 
nos el que en 1553 Samuel Usque ${ }^{14}$ considere pequeñas las tribulaciones presentes comparadas con otras del pasado histórico judío:

pode verificar he na nossa trabalhada ... naçaõ, aqual ynda que nestes nossos dias padeça graues tribulaçoẽs, todavia muito moores foram aquellas que ja pellos nossos antiguamente passarom, pello que estas se podem reputar por piquenas.

Entre el apóstata sincero y el fingido está el tibio y el indiferente, porque ya no cree en ninguna de las dos religiones, ni la anterior ni la nueva. Posiblemente de este tipo era Davihuelo, converso del siglo XV del que en el Cancionero de Baena el poeta Alfonso Álvarez de Villasandino dice: "A Dios non teme, nin creo / qu'el sus Evangelios crea».

Desde los tiempos de las persecuciones romanas, según los Padres de la Iglesia, el cristiano está obligado al martirio antes que abjurar de su religión; no debe ir en busca de la muerte, pero sí debe afrontarla si llega el caso. En una sociedad cristiana moralmente obligada al martirio, tenía que herir el comprobar que numerosos conversos eran fingidos, por miedo o por interés, y que seguían siendo judíos; y que el trato con los judíos producía en los conversos ingenuos atracción hacia su antigua fe. Por parte judía hay al menos un caso en que se teme el efecto contrario: rabí Simón ben Semaḥ Durán recomienda en 1413 a los judíos de Mallorca que no se junten con los marranos o chuetas ${ }^{15}$. El peligro del contacto del converso con el judío es el que sirve de justificación a los Reyes Católicos para la expulsión de los judíos. Era una realidad que no solamente está en el Edicto de expulsión, sino que expresamente lo reconocían los propios judíos. Yosef ha-Kohen, que escribe en hebreo, lo dice claramente ${ }^{16}$ :

Pusieron estos dos reyes [Católicos] inquisidores sobre los conversos para ver si seguían sus costumbres o no ... Viendo estos príncipes que se habían asociado muchos a la Casa de Israel, desterraron a

\footnotetext{
${ }^{14}$ Consolaçam as tribvlaçoens de Israel composto por Samvel Vsqve, Ferrara 5313 [= 1553], Prólogo "Aos Senhores do desterro de Portugal».

${ }^{15}$ I. EPSTEIN, The Responsa of Rabbi Simon b. Zemah Duran as a Source of the History of the Jews in North Africa, 1930 [reimpresión New York 1968], pág. 42.

${ }^{16}$ P. LeÓN Tello, 'Emeq ha-bakha, pág. 176.
} 
los judíos de su tierra para que no volvieran a marchar los conversos por las vías de aquéllos, como habían hecho hasta entonces.

El cristianismo había heredado la obligación del martirio, si llegaba el caso, del judaísmo antiguo. Y esta idea seguía imperando en las comunidades judías centroeuropeas. Si leemos El valle del llanto, donde se resumen las crónicas de las persecuciones ${ }^{17}$, veremos con cuánta mayor frecuencia se da el martirio entre los judíos askenazíes que entre los sefardíes. En Worms, en 1096, cuando los cruzados devastan las juderías por donde pasan, los judíos

prefiriendo la muerte a la vida, rehusaron apartarse de su Dios; suicidáronse muchos; otros, mataron a su hermano o a su amigo; algunos a su mujer entrañable y a sus hijos e hijas; mujeres caritativas degollaron a sus hijitos con valentía y ánimo; decían el Escucha, Israel mientras iban a reunirse sus almas al seno de sus madres (cap. 24).

En Maguncia, un tal Urí y otro Ishaq se convirtieron a la fuerza para salvarse, pero arrepentidos después,

Ishaq inmoló a sus hijas ... encendió un fuego en su casa y las ofreció en holocausto a Dios. Marchó también Urí, su amigo, al Templo delante del Tabernáculo y murieron ante Dios; cuando subió la llama, sus almas se elevaron al cielo (cap. 25).

En Colonia, cogieron a uno que no quiso huir y llevado a la iglesia «escupió a sus ídolos, blasfemó y los ultrajó, y ellos lo mataron» (cap. 26). En Elenda cogieron a un rabino y, cuando por el dolor de los tormentos estaba inconsciente, lo bautizaron: «Al tercer día volvió su espíritu a su ser. Marchó al río Rin, se echó al agua y murió» (cap. 29). En Würzburg (1147) una judía quedó desvanecida a fuerza de golpes y la bautizaron; ella fingió estar muerta y fue salvada por una cristiana que se conmovió: «Los otros judíos se escondieron en casa de sus amigos y al día siguiente huyeron ...

\footnotetext{
${ }^{17}$ Las correspondientes a las primeras cruzadas están estudiadas por A. M. HABERMANN, Sefer gězerôt 'aškenaz wë-sarfat , Jerusalem 1946. Recordemos que una gran parte del material de Yosef ha-Kohen está traído de la citada obra de Samuel Usque, Consolaçam as tribvlaçoens de Israel, escrita en portugués.
} 
hasta que pasó el furor y Dios los salvó» (cap. 47). Éste era el ánimo predominante en Centroeuropa.

Jacob Katz ${ }^{18}$ ha recogido las opiniones de los rabinos jurisperitos de las comunidades franco-germanas en los casos de persecución y de invitación a la conversión al cristianismo, y la oposición teológica que esto les merecía. Como los cristianos eran considerados como idólatras, se hacía muy difícil el paso al cristianismo. Cuando durante las cruzadas se produjeron conversiones en grupos numerosos, el emperador Enrique IV los autorizó a volver al judaísmo. Tanto las conversiones en grupos como las individuales a lo largo de los siglos no llegaron a producir en Centroeuropa, contrariamente a lo que ocurrió en España, ni por su número ni por su talante, una unidad social reconocible en la sociedad cristiana. El ambiente popular judío era francamente hostil al mumar o měšsmmad, pero las autoridades rabínicas estimaron que la condición de judío no se perdía por el bautismo, y el apóstata estaba obligado a volver al redil judío. Rabbenu Geršom Me’or ha-Golâ impuso el criterio de que la doctrina del arrepentimiento estaba por encima del castigo a los apóstatas; Raší y otros siguieron este criterio. Rabí Natán de Roma propuso que el apóstata fuera considerado gentil, no judío, pero no prosperó su punto de vista. En todo caso, son opiniones para aplicar a posteriori que en nada facilitan la propensión a la conversión simulada.

En la doctrina del martirio es donde más divergen los judíos centroeuropeos de los españoles. En el Talmud, rabí Ismael declara que se puede simular la conversión si hay menos de diez testigos, pero esta opinión tiene en contra suya a todos los rabinos askenazíes, que no admiten que tan grave asunto se deje a que haya o no el número suficiente de testigos. Jacob Katz señala que la educación askenazí preparaba ya al niño para el caso de un posible martirio: se les contaba el caso de la madre y sus siete hijos mártires del segundo libro de los Macabeos (cap. 7) y la muerte de rabí Aquibá en época romana; por otra parte, la sociedad askenazí, más inculta, no racionalista, consideraba que el mundo venidero no era algo abstracto, sino una realidad viva que se alcanzaba en el momento del martirio; pero aún así, se debía recurrir a todos los medios -autoridades, amigos, sobornos- para evitar el martirio; pero si

18 J. KATZ, Exclusiveness and Tolerance. Studies in Jewish-Gentile Relations in Medieval and Modern Times, Oxford 1961. 
todo fallaba y éste llegaba, se aceptaba como un decreto divino e incluso era lícito el suicidio antes que ser bautizado; si llegaba el momento del martirio, se moría recitando la šěmac y blasfemando horriblemente de Jesús y de la Iglesia.

No era éste, evidentemente, el ambiente de los judíos españoles. El judío converso forzado que recibe ahora el nombre de 'anûs 'forzado', conserva sus derechos de judío mientras no se demuestre públicamente su apostasía voluntaria, y si no huye de donde está, no hay que reprochárselo, pues en opinión de rabi Simón ben Șemaḥ Durán, quizás no tuvo medios económicos, o lo intentó y fracasó, o temió que la posibilidad de huir que le ofrecían fuese una trampa, y en todo caso ¿quién sabe los motivos que tenía para quedarse?, solamente «el corazón conoce su propia amargura».

En el libro de Moisés Orfali (nota 11) se recogen las diversas opiniones de los rabinos españoles acerca de los conversos, que varían en detalles jurídicos sobre tutela de hijos, casamientos, herencias, etc., pero que en todas prevalece una cierta comprensión hacia el converso, del que con dificultad se acepta que 1o seá vuluntariamente. Predomina la influencia de las ideas de Maimónides y de su padre, rabí Maimón, tendentes a suavizar la situación del converso y a ser comprensivo con él. El último de los rabinos españoles estudiado por Orfali es Sacadia ibn Danán, de Granada, de donde salió en 1492 camino de Orán. Sacadia ibn Danán se opone a los que consideraban a los conversos 'anûsîm como renegados, tratándolos como goyyîm 'gentiles', menos aún que los měšummadîm 'avasallados'. Ibn Danán opina que los conversos siguen manteniendo su judaísmo y no se les puede desesperanzar en sus esfuerzos por volver o por mantener sus creencias en la medida de sus posibilidades. Según Orfali, después de la expulsión, ésta es la actitud prevalente entre los refugiados en el Imperio Turco. En los detalles, había discrepancias en cuanto al grado de judaísmo o gentilidad que había que conceder a los que se habían quedado en España cumpliendo como cristianos.

\section{EL PRECEDENTE MUSULMÁN DEL DISIMULO}

Como escribe el P. Félix Pareja, la apostasía es la muerte civil absoluta en el Islam, y se requiere la denuncia de dos testigos de 
excepción para declarar a alguno apóstata del islamismo. Sin embargo, y es dato que hay que tener en cuenta, en el Corán, en la sura 16 (La abeja), aleya 108, se dice:

Los creyentes que hayan caído en la apostasía sabrán cuán formidable es la ira del cielo, a menos que, cediendo a la violencia, sus labios hayan negado la fe que guardaban los corazones ${ }^{19}$.

Por ello las escuelas jurídicas musulmanas salvan a aquel que pueda demostrar con testigos que sufrió violencia y apostató a la fuerza. Permite, pues, el Islam la simulación de la conversión, el disimulo (taqĩya) prudente de la propia religión si hay peligro de muerte. Esta doctrina musulmana salvó a Maimónides en Egipto: cuando fue nombrado naguid o representante de los judíos, y acusado de apóstata del Islam se tuvo en cuenta que su islamismo había sido simulado.

\section{LA JUSTIFICACIÓN DE MAIMÓNIDES}

Como es sabido, poco antes de mediados del siglo XII la España musulmana sufre dos invasiones de fervorosos musulmanes norteafricanos. La primera es la de los almorávides, que eliminan a los cristianos mozárabes, pero dejan a los judíos; la segunda la de los almohades, que consideran que también los judíos han de hacerse musulmanes o salir del país, bajo pena de muerte. Los judíos, entre ellos Maimónides, fueron dando largas al asunto hasta que no tuvieron más remedio que marcharse a la España cristiana, a otros países árabes, o islamizar. Maimónides simuló la conversión al Islam e incluso mantenía conversaciones con los teólogos musulmanes sobre puntos de fe musulmana. Por ello, cuando en 1165 es acusado de no ser buen musulmán, el teólogo musulmán Ibn Moisa le salva la vida saliendo garante de la ortodoxia de Maimónides. Pero este mismo Ibn Moisa cuando lo volvió a encontrar en Egipto

${ }^{19}$ F. M. PAREJA, La religiosidad musulmana, Madrid 1975. Expuse por primera vez la influencia de la norma musulmana sobre los judíos españoles en mi conferencia "¿Por qué los hispano-judíos fueron más tolerantes con las conversiones simuladas?» dada en Barcelona (Amistad judeo-cristiana) el 17 de mayo de 1978; en el Prólogo del libro de M. Orfali, Los conversos españoles, citado en nota 11, hago una breve alusión. 
se sorprende de verle convertido en naguid o representante político de los judíos y, puesto que él lo había conocido como musulmán, le acusa de haber cometido apostasía respecto del Islam. Pero las autoridades musulmanas estimaron que nunca había sido musulmán, puesto que se ejerció violencia sobre él, de modo que podía seguir como naguid, cargo que obtuvo con la protección del visir de Saladino al-Fadll. Así pues, Maimónides se benefició de un concepto musulmán, el de la taqùya o disimulo prudente de la propia fe.

La primera vez que se les plantea a los judíos colectivamente la disyuntiva de cambiar de religión o desaparecer es en Marruecos y la España musulmana y por los fanáticos almohades. Los que se quedaron y no emigraron trataron de aparecer externamente como musulmanes y en el interior seguir siendo judíos. Pero ésta era una situación espiritualmente insatisfactoria para muchos, mientras que para otros significaba una paulatina difuminación de lo que era judío y de lo que era musulmán. Rabí Maimón ha-Dayyán (m. 1165) escribe en Fez en 1160 una epístola en árabe, la 'Iggeret nẹhamâ ('Epístola de la consolación') ${ }^{20}$, cuyos puntos principales son:

Dios no nos odia ... ni cuando nos apartamos de El ... debemos tener esperanza y entonces reposarán las almas desesperanzadas ... estamos en el destierro, nos parecemos al que se ahoga y ya nos hundimos casi hasta la nariz ... si no hubiera sido por la oración, Daniel no se hubiera expuesto al peligro ... y basta a quien no sepa y no quiera quedarse sin unirse a Dios ... no hay cosa más honrosa para el Santo bendito sea que la oración.

Así pues, la oración es el medio para los que siendo musulmanes aparentes quieren seguir siendo judíos. Es, en cierto modo, la aplicación al judaísmo del disimulo musulmán. El hijo del juez Maimón, Moseh ben Maimón o Maimónides, escribe también en árabe otra epístola, luego traducida al hebreo, 'Iggeret ha-š̌mad: Ma'amar qiddûš ha-Šem ('Epistola de la apostasía: Tratado del martirio') ${ }^{21}$. En ella, Maimónides disculpa la apostasía impuesta por los almohades alegando que es puramente formal. Con su Epístola trata de defender

\footnotetext{
${ }^{20}$ Epístola de la Consolación, traducida al hebreo en 1905 por B. KLAR y Y. L. HA-KOHEN FrišMAN.

${ }^{21}$ Sigo la edición crítica y estudio de M. D. RabinoviTz, Jerusalem 1960. Una reciente traducción castellana puede leerse en M. ${ }^{a}$ J. Cano - D. Ferre, Cinco Epístolas de Maimónides, Barcelona 1988.
} 
a esos apóstatas, a él mismo en realidad, del rigorismo de algunos rabinos que recordaban que la norma judía exige el martirio antes que la apostasía. Para Maimónides esta apostasía es distinta de la de los tiempos antiguos, pues no obliga a transgredir los preceptos de un modo activo: la apostasía de ahora no obliga activamente, sino solamente de palabra. Y si se quiere cumplir los 613 preceptos secretamente, se cumplen y no se fuerza a transgredir el sábado. Están seguros los musulmanes de que nosotros no creemos en tal declaración (de fe musulmana) y de que no se pronuncia sino como forma de salvarse del rey y aplacarle. El que no acepte y sea asesinado hizo lo recto y tendrá un gran premio ante Dios,

pero a todo aquel que venga a preguntarnos si ha de ser asesinado o ha de reconocer [al Islam], le decimos: que reconozca y no sea asesinado ... El consejo que yo me doy a mí mismo y la opinión que yo quiero para mí y para mis amados y para todos cuantos me piden consejo es: que salga de estos lugares, marche a un lugar que posibilite la permanencia de su religión ... aunque no mantuviera el precepto del martirio, no se le llamará profanador del nombre de los cielos voluntariamente ... No es conveniente alejar a los profanadores del sábado, ni rechazarlos, sino que hay que acercarlos y alentarlos para cumplir los preceptos ... al pecador ... no se debe acostumbrar a vejarlo.

Este cariño en el trato contrasta con el rechazo popular del judaísmo askenazí. Y esa diferencia solamente tiene una explicación: la profunda arabización de Maimónides ${ }^{22}$, que, inconscientemente quizás, le llevó a aceptar por motivos prácticos la solución de la taqĩya musulmana para la situación de los judíos enredados en la intolerancia almohade. La influencia de Maimónides en todo el judaísmo español, también fuertemente arabizado, explica la tolerancia, cuando no la complicidad, de los judíos con los conversos fingidos. En la España cristiana, donde la aceptación de la obligación del martirio era preceptiva para los cristianos, no se justificaba la simulación en una materia que para ellos era de vida o muerte ${ }^{23}$. La

\footnotetext{
${ }^{22}$ Mientras que Abraham ibn Daud y los Ibn Tibbón y los Qimhí, entre otros muchos, buscaron refugio en la España cristiana o en Provenza, Maimónides prefirió quedarse en territorio arábigo-musulmán.

${ }^{23}$ La doctrina de la Iglesia era contraria a las conversiones forzadas, pero en esto, como en la caridad o la castidad, entre los cristianos la pasión se impone a la reflexión con mucha frecuencia.
} 
simulación constituía socialmente un escándalo. De ahí el cambio en la Inquisición, las propuestas de los estatutos de limpieza de sangre y en última instancia, el destierro. ¡Quién iba a pensar que el lejano culpable sería el arabizado Maimónides!

\section{RESUMEN}

La expulsión de los judíos de España en 1492 fue precedida por la de Inglaterra (1290) y Francia (1394). La actitud ante el martirio en los cristianos y en el judaísmo tradicional era la de preferir la muerte a la apostasía, mientras que en el Islam se admite el disimulo si hay grave peligro. En contraste con los judíos askenazíes, los sefardíes aceptaron la opinión de Maimónides, influido por la taqũya o disimulo musulmán. La abundancia de falsos conversos llevó a la expulsión.

\section{SUMMARY}

The expulsion of the Jews from Spain in 1492 was preceded by the one from England (1290) and France (1394). In Christianity and in traditional Judaism, death was to be preferred to apostasy, but Islam accepted dissimulation when a serious danger threatened. In contrast with Askenazi attitude, the Sephardic Jews accepted Maimonides' opinion, influenced by the taquya or muslim dissembling. The great plenty of false conversos led to the expulsion. 